\title{
DANO MORAL DECORRENTE DO DESCUMPRIMENTO DO CONTRATO DE PRESTAÇÃO DE SERVIÇOS EDUCACIONAIS EM INSTITUIÇÕES PRIVADAS DE ENSINO SUPERIOR
}

\author{
Fabrício Veiga Costa ${ }^{1}$ \\ Érica Patrícia Moreira de Freitas ${ }^{2}$
}

\section{Resumo}

A relação jurídica existente entre discente e instituições privadas de ensino superior é regida pela Lei 8078/90. O descumprimento do contrato de prestação de serviços educacionais poderá ou não acarretar o dano moral. Sempre que a ilicitude violar direito da personalidade ou direito fundamental, comprovando-se o nexo de causalidade do ilícito com o dano, caberá ao agente o dever de indenizar na proporção e na extensão do prejuízo sofrido. A responsabilidade civil objetiva dispensa a comprovação da conduta dolosa ou culposa do agente. Ilicitudes que causam mero aborrecimento não são passíveis de reparação.

Palavras-Chave: Contrato de Prestação de Serviços Educacionais; Instituições Privadas de Ensino Superior; Dano Moral; Mero Aborrecimento; Lei 8078/90.

\section{MORAL DAMAGE RESULTING FROM THE BREACH OF THE CONTRACT FOR THE PROVISION OF EDUCATIONAL SERVICES IN PRIVATE INSTITUTIONS OF HIGHER EDUCATION}

\begin{abstract}
The legal relationship between students and private higher education institutions is governed by Law 8078/90. Failure to comply with the contract for the provision of educational services may or may not result in moral damages. Whenever the unlawfulness violates the right of

\footnotetext{
${ }^{1}$ Pós-Doutorado em Educação pela UFMG (2015). Doutorado em Direito Processual (2012) pela Pucminas. Mestrado em Direito Processual (2006) pela Pucminas. Especialista em Direito Processual (2003), Direito de Família (2009) e Direito Educacional (2013) pela Pucminas. Bacharel em Direito pela Universidade Federal de Uberlândia (2001). Professor do Programa de Pós-graduação stricto sensu em Proteção dos Direitos Fundamentais da Universidade de Itaúna -MG-.

${ }^{2}$ Mestrado em Letras e Linguística pela Pucminas. Mestranda em Proteção dos Direitos Fundamentais pela Universidade de Itaúna. Especialista em Direito Processual pelo IEC-Pucminas. Especialista em Revisão de Texto pelo IEC-Pucminas. Especialista em Educação à Distância pela FAEL. Especialista em Metodologia da Linguagem pela FAEL. Bacharel em Direito e Letras pela Pucminas.
} 
personality or fundamental right, proving the causal link of the wrong with the damage, it will be incumbent upon the agent to indemnify the proportion and extent of the damage suffered. Objective civil liability dispenses the evidence of the deceitful or guilty conduct of the agent. Ilicitudes that cause mere annoyance are not amenable to redress.

Keywords: Agreement for the Provision of Educational Services; Private Institutions of Higher Education; Moral damage; Mere Hassle; Law 8078/90.

\section{Introdução}

O objetivo geral da presente pesquisa é investigar a problemática jurídica do dano moral no âmbito das instituições de ensino superior privadas, demonstrando situações nas quais o descumprimento do contrato de prestação de serviços educacionais enseja a pretensão indenizatória de danos morais.

A escolha do tema justifica-se em razão de sua relevância prática e teórica, além da necessidade de esclarecer a distinção existente entre dano moral e mero aborrecimento no âmbito institucional. Pretende-se demonstrar especificamente que nem sempre o descumprimento do contrato de prestação de serviços educacionais viabiliza a pretensão indenizatória, haja vista que existem situações de ilicitude que não ensejam a ofensa a direitos fundamentais ou direitos da personalidade.

A pergunta problema que norteará o debate proposto é a seguinte: quando e em quais situações se torna juridicamente viável demonstrar que o descumprimento do contrato de prestação de serviços educacionais, por instituições privadas de ensino, configura o dano moral? Para responder a tal indagação é importante esclarecer as peculiaridades jurídicolegais que permeiam o contrato de prestação de serviços pelas instituições superiores privadas de ensino, demonstrando a existência de cláusulas específicas e obrigações particulares assumidas pelos discentes, docentes e pela própria instituição.

Tal modalidade de contrato é regida pelo Código de Defesa do Consumidor, algo fundamental para reconhecer a condição de consumidor ao discente, considerado vulnerável e a parte que se encontra em posição de desigualdade frente à instituição de ensino. A compreensão casuística da hipossuficiência do consumidor oportuniza-lhe o direito de requerer a inversão do ônus da prova em processo judicial. A responsabilidade civil objetiva, 
preconizada pela Lei 8078/90, dispensa a comprovação da culpa do agente, quando demonstrado o nexo de causalidade entre a conduta ilícita e o dano sofrido.

Nesse contexto foi necessário identificar quais cláusulas contratuais violadas e situações ocorridas são suficientes a ensejar a pretensão de danos morais, assim como se torna relevante destacar as hipóteses em que resta demonstrado mero aborrecimento, não passível de reparação civil.

A realização da pesquisa bibliográfica foi essencial para buscar fundamentos na doutrina no sentido de compreender os princípios regentes do contrato de prestação de serviços educacionais; justificativas da aplicabilidade do Código de Defesa do Consumidor na relação contratual instituída entre discente e instituições privadas de ensino superior; entendimento dos requisitos jurídico-legais voltado ao estudo crítico-sistemático do dano moral no Brasil.

Por meio da pesquisa documental foi possível interpretar comparativamente legislação e julgados sobre o tema proposto, de modo a diferenciar situações de dano moral e mero aborrecimento decorrentes do descumprimento do contrato de prestação de serviços educacionais. A utilização do método dedutivo viabilizou a delimitação do problema teórico, partindo-se de uma concepção macroanalítica, qual seja, o estudo do dano moral, delimitandose o objeto de estudo na problemática do dano moral no âmbito das instituições privadas de ensino superior.

\section{Peculiaridades jurídico-legais do Contrato de Prestação de Serviços Educacionais pelas Instituições Privadas de Ensino Superior.}

O presente capítulo tem o condão de analisar as nuances e peculiaridades atinentes aos contratos de prestação de serviços educacionais em Instituições de Ensino Superior Privadas. Trata-se de contrato de adesão $^{3}$, ou seja, o contratante adere a todas as cláusulas

\footnotetext{
${ }^{3} \mathrm{O}$ contrato de adesão é o instrumento muito adotado nas relações de consumo. São elaborados, geralmente por uma das partes (proponente) e são usados no dia a dia das relações de consumo, pois já estão em modelos prontos para garantir a agilidade e execução dos negócios. Segundo Caio Mário (1), o contrato de adesão deveria se chamar contrato por adesão, assim entendido ", aqueles que não resultam do livre debate entre as partes, mas provêm do fato de uma delas aceitar tacitamente as cláusulas e condições previamente estabelecidas pela
} 
contratuais propostas pelo contratado como condição para a constituição da relação contratual, que no entendimento preconizado pelo jurista Silvio de Salvo Venosa "Trata-se do típico contrato que se apresenta com todas as cláusulas predispostas por uma das partes. A outra parte, o aderente, somente tem a alternativa de aceitar ou repelir o contrato” (2011, p. 393).

Muitas vezes, esse tipo de relação jurídica desencadeia o desequilíbrio da relação contratual, haja vista que o contratante (discente) se submete a todas as cláusulas contratuais propostas pelo contratado (Instituição de Ensino Superior Privada) com o propósito de realizar o sonho de obtenção do grau superior em sua formação escolar. Tal modalidade de relação contratual é freqüentemente objeto de ações judiciais, momento em que o contratante busca a revisão judicial das cláusulas pautada na premissa de desequilíbrio da relação contratual em virtude da violação dos princípios da boa fé objetiva e isonomia contratual. “O controle judicial não se manifestará apenas no exame das cláusulas contratuais, mas desde a raiz do negócio jurídico” (VENOSA, 2011, p. 384).

Não se pode deixar de ressaltar que a relação jurídica instituída entre o discente a e instituição de ensino é de natureza consumeirista, haja vista que o contratante adquire serviço educacional do contratado como destinatário final. Em razão disso, sabe-se que o discenteconsumidor faz jus a determinadas prerrogativas inerentes às relações consumeiristas, tais como a condição de hipossuficiente, vulnerabilidade, direito a inversão do ônus da prova e a responsabilidade objetiva do fornecedor.No momento em que se constitui validamente a relação contratual entre as partes sabe-se que entre elas são instituídas reciprocamente obrigações.

À contratada cabe a obrigação de prestação dos serviços educacionais conforme oferecido, ou seja, por se tratar de uma relação consumeirista a oferta vincula o fornecedor ao seu regular cumprimento.

No caso de cursos presenciais, o contratado assume a obrigação de prestar o serviço educacional de forma que o docente ministre todo o conteúdo constante no plano de ensino de cada disciplina; o docente tem a obrigação de conduzir, em nome da Instituição de Ensino, todo o processo ensino-aprendizagem, de modo a ser pontual quanto ao horário regular das aulas, lançamento de notas no sistema-aula, aplicação e correção de avaliações e trabalhos,

outra". (PRETTI, 2014) Disponível em http://www.direitonet.com.br/artigos/exibir/725/O-contrato-de-adesaono-Codigo-Brasileiro-de-Defesa-do-Consumidor. Acesso em 17 jun. 2017. 
entrega das avaliações e trabalhos acadêmicos devidamente corrigidos aos discentes e, acima de tudo, a prestação do serviço de qualidade.

Ao discente de cursos presenciais cabe o cumprimento das obrigações assumidas contratualmente, dentre as quais ressaltamos: freqüência e assiduidade mínima nas aulas previamente agendadas; participação nas aulas ministradas pelo docente; realização das provas e trabalhos acadêmicos propostos pelo docente.

No que tange aos cursos à distância destaca-se que as obrigações assumidas pela instituição de ensino superior consistem em disponibilizar uma plataforma virtual eficiente à realização, pelo discente, do estudo das disciplinas e atividades avaliativas; disponibilizar, a partir do cronograma proposto, todo o material didático-pedagógico suficiente aos estudos e às atividades avaliativas propostas. Em contrapartida, o discente assume as seguintes obrigações contratuais: entregar tempestivamente as atividades avaliativas propostas; realizar as provas presenciais, eventualmente existentes; participar de todas as discussões acadêmicas propostas na plataforma virtual, dentre outras obrigações.

É nesse contexto jurídico que se torna relevante o debate dos princípios do consensualismo ${ }^{4}$ e da bilateralidade como referenciais teóricos hábeis a assegurar a validade jurídica e o cumprimento dos contratos ora firmados entre as partes.

O contrato materializa a manifestação livre das pessoas definirem com quem querem e o que querem contratar. A liberdade das pessoas quererem contratar, aliada com a liberdade de com quem pretendem contratar e o estabelecimento do conteúdo do contrato são pressupostos básicos da validade jurídico-legal de qualquer relação jurídico-contratual.

Nesse contexto Pablo Stolze Gagliano é pontual e categórico ao afirmar que “a autonomia privada e o consensualismo permanecem como base da noção de contrato, embora limitados e condicionados por normas de ordem pública em benefício do bem-estar comum” (GAGLIANO; PAMPLONA FILHO, 2006, p. 36). Nesse mesmo sentido afirma Silvio de Salvo Venosa: “a vontade contratual somente sofre limitação perante uma norma de ordem pública” (2011, p. 383), haja vista que a intervenção do Estado no que atine ao controle do

\footnotetext{
${ }^{4}$ Princípio do consensualismo: segundo o qual o simples acordo de 2 ou mais vontades basta para gerar o contrato válido. $\quad$ Disponível em http://www.centraljuridica.com/doutrina/78/direito_civil/conceito_requisitos_principios_dos_contratos.html. Acesso em 20 jun. 2017.
} 
conteúdo e da validade jurídica dos contratos somente se justifica quando resta evidentemente clara a violação de normas jurídicas cogentes (violação e ofensa aos Direitos Fundamentais; Fundamentos e Objetivos Fundamentais da República Federativa do Brasil; princípios constitucionais, Direitos da Personalidade).

Esse consenso existente entre as partes e a observância do princípio ético regente das relações contratuais é conditio sine qua non para garantir o regular cumprimento daquilo que foi contratado, ou seja, o princípio do consensualismo estabelece que "o simples acordo de duas ou mais vontades basta para gerar um contrato válido” (DINIZ, 2008, p. 29). Implica em dizer que o discente tem a expectativa de receber aulas ministradas com qualidade e conteúdo teórico suficiente a lhe permitir e a oferecer condições ao exercício regular da profissão escolhida. Torna-se necessário que o docente se comprometa com o exercício de suas atividades laborativas, de modo a proporcionar ao discente todas as habilidades necessárias em cada disciplina proposta, visando o preparo ao exercício da profissão. Ressalta-se que a obrigação assumida pela instituição de ensino é de meio, não de resultado.

É fundamental que o docente seja preparado para a condução de cada disciplina do curso, claro quanto às regras regentes do sistema de avaliação e comprometido o suficiente no que tange à devolução de provas e atividades avaliativas corrigidas, assim como o lançamento regular das notas e controle de freqüência para os cursos presenciais.

Nos cursos a distância e nas disciplinas oferecidas na plataforma virtual a instituição de ensino precisa ter um cuidado ainda maior no que se refere à condução do processo ensinoaprendizagem. Deve oferecer ao aluno um acompanhamento pedagógico e acadêmico suficientemente efetivo para lhe proporcionar condições de cursar a disciplina ou o próprio curso à distância, seja através da plataforma virtual ou mediante encontros presenciais com o professor titular de cada disciplina.

A liberdade contratual das partes é corolário da legitimidade que as mesmas têm de auto-regulamentação dos seus próprios interesses nos limites da lei. O princípio da autonomia privada, consectário do Direito Fundamental a Liberdade, funda-se na "liberdade contratual dos contratantes, consistindo no poder de estipular livremente, como melhor lhes convier, mediante acordo de vontades, a disciplina de seus interesses, suscitando efeitos tutelados pela ordem jurídica” (DINIZ, 2008, p. 23). 
Verifica-se que não é ilimitada e absoluta a liberdade das partes contratarem, visto que é limitada à supremacia da ordem pública, referencial teórico esse que proíbe a realização de contratos contrários aos costumes, Direitos Fundamentais, princípios e garantias constitucionais e Direitos da Personalidade.

É sabido que, embora os contratos visem resguardar direta e imediatamente os interesses individuais, a vontade dos contratantes fica subordinada ao interesse coletivo, ou seja, secundária e mediatamente qualquer relação contratual tem a sua validade jurídica condicionada à função social do contrato.

É nesse cenário jurídico, pautado na liberdade de contratar, regulamentada pelo dirigismo contratual, que se torna necessário compreender as peculiaridades jurídicas do contrato de adesão de prestação de serviços educacionais, de modo a conduzir tal reflexão nos moldes propostos pelos princípios da isonomia contratual e boa-fé objetiva.

\section{Aplicabilidade do Código de Defesa no Contrato de Prestação de Serviços}

\section{Educacionais.}

A relação jurídica instituída entre Instituição de Ensino e discente é de natureza consumeirista e, por isso, possui especificidades previstas no Código de Defesa do Consumidor. Segundo estabelece a Lei 8078/90 (Código de Defesa do Consumidor), em seu artigo $2^{\circ}$, considera-se consumidor toda pessoa física ou jurídica que adquire ou utiliza produto ou serviço como destinatário final. No que se refere ao objeto da presente pesquisa sabe-se que o discente é considerado juridicamente consumidor na relação estabelecida com a Instituição de Ensino Superior Privada, uma vez que o mesmo adquire a prestação dos serviços educacionais com o destinatário final.

Na mesma seara, estabelece o artigo $6^{\circ}$ da Lei 8078/90 que fornecedor é toda pessoa física ou jurídica, pública ou privada, nacional ou estrangeira, assim como os entes despersonalizados, que desenvolvem atividades de produção, montagem, criação, construção, transformação, importação, exportação, distribuição ou comercialização de produtos ou prestação de serviços. Destaca-se nesse contexto que a Instituição de Ensino Superior Privada assume a posição de fornecedor na relação jurídica instituída com o discente, uma vez que se trata de pessoa jurídica que presta serviços educacionais. 
Conforme se depreende do inciso I, do artigo $4^{\circ}$ da Lei 8078/90, o consumidor é considerado vulnerável, uma vez que na relação jurídica de consumo tem proteção especial porque é visto como a parte mais frágil, na medida em que não tem acesso ao sistema produtivo e, a priori, não conhece o funcionamento e as especificidades técnicas do produto ou serviço adquirido como destinatário final.

No entendimento de Julio Moraes Oliveira “a ideia de vulnerável está diretamente ligada à ideia de submissão ou falta de controle sobre o processo produtivo” (2014, p. 58). Trata-se de um princípio corolário do direito à igualdade nas relações consumeiristas, haja vista que vulnerável é exatamente aquela pessoa (consumidor) que se encontra em posição desigual na relação jurídica então instituída entre as partes. "Em outras palavras, vulnerabilidade é a situação na qual um dos sujeitos de determinada relação figura em pólo mais frágil - e, em virtude disso, carece de cuidados especiais, o que deve ser preocupação do legislador e do aplicador da lei que garante a proteção” (MANASSÉS, 2014) 5 .

Não se pode afirmar que a vulnerabilidade é um conceito e um direito que visa trazer privilégios ao consumidor, uma vez que ao longo de todo o processo produtivo no sistema capitalista é claro que quem detém os meios de produção se encontra faticamente em posição hierarquicamente superior à parte que recebe, adquire ou consome o que foi produzido ao longo de todo esse sistema produtivo.

O consumidor é exatamente esse sujeito que se encontra na ponta de todo o sistema de produção, quem recebe aquilo que foi produzido, quem não teve oportunidade de participar e conhecer todas as peculiaridades de como o bem ou serviço oferecido foi produzido antes de lhe ser disponibilizado.

A vulnerabilidade foi construída exatamente com o condão de equalizar as desigualdades fáticas que marcam o sistema produtivo das relações jurídicas constituídas entre consumidor e fornecedor. O que pretendeu o legislador foi exatamente assegurar ao consumidor uma proteção jurídica suficientemente legitima a lhe conceder igualdade jurídica nas relações consumeiristas, fato esse que afasta qualquer colocação ou alegação no sentido de que a vulnerabilidade constitui um privilégio concedido pela lei ao consumidor.

Todo consumidor é considerado juridicamente vulnerável, embora não possa ser visto sempre como hipossuficiente, uma vez que o conceito de hipossuficiência é depreendido

5 Disponível em http://www.conteudojuridico.com.br/artigo,vulnerabilidade-hipossuficiencia-conceito-deconsumidor-e-inversao-do-onus-da-prova-notas-para-uma-diferenciac,43983.html. Acesso em 25 jun. 2017. 
muito mais de uma análise fática do caso concreto do que propriamente decorrente de uma compreensão exclusivamente jurídica da relação consumeirista. "Trata-se de um conceito fático e não jurídico, fundado em uma disparidade ou discrepância notada no caso concreto” (MANASSÉS, 2014) ${ }^{6}$.

Hipossuficiente é aquele consumidor que demonstra no caso concreto desconhecer a técnica ou informações relevantes do produto ou serviço por ele adquirido, de modo a colocálo em posição jurídica de desigualdade perante o fornecedor. É por isso que a hipossuficiência é auferida casuisticamente, de modo que, uma vez constatada, assegura ao consumidor o direito à inversão do ônus da prova.

O consumidor não pode ser visto como um sujeito de direitos que conhece tecnicamente todo produto ou serviço por ele adquirido. Sabe-se que, na maioria das vezes, adquire bens e serviços desconhecendo as questões técnicas atinentes ao objeto da relação consumeirista. Por isso, a informação é vista juridicamente como um Direito Fundamental, através do qual o consumidor precisa tomar conhecimento de todas as informações atinentes ao objeto do contrato, de modo que as partes se comportem nos moldes estabelecidos pelo principio da boa-fé objetiva, que "importa na exigência do dever de lealdade entre os contratantes com respeito às expectativas legítimas geradas no outro” (OLIVEIRA, 2014, p. 68).

A transparência e a confiança nas relações contratuais regidas pelo Código de Defesa do Consumidor são corolários do princípio da boa-fé objetiva. Há uma simbiose entre o Direito à informação e o princípio da transparência, que se materializa por meio da “informação clara, correta e precisa acerca dos produtos e serviços como, por exemplo: a informação acerca da quantidade exata, características, composição, tributos incidentes, preços, formas de pagamento e também sobre os riscos que os mesmos apresentam” (OLIVEIRA, 2014, p. 85).

A confiança ${ }^{7}$ é outro princípio regente das relações contratuais consumeiristas, uma vez que tem o condão de proteger o consumidor diante de práticas abusivas e lesivas aos seus

6 Disponível em http://www.conteudojuridico.com.br/artigo,vulnerabilidade-hipossuficiencia-conceito-deconsumidor-e-inversao-do-onus-da-prova-notas-para-uma-diferenciac,43983.html. Acesso em 25 jun. 2017.

7 Também é direito básico do consumidor relacionado à confiança a proteção contra a publicidade enganosa e abusiva, métodos comerciais coercitivos ou desleais, bem como contra práticas e cláusulas abusivas impostas no 
direitos previstos no plano legislativo. Considerando-se a vulnerabilidade como critério jurídico regente das relações de consumo, bem como a hipossuficiência fático-casuística do consumidor, sabe-se que o mesmo se encontra em posição de desigualdade jurídica perante o fornecedor e, por isso, adquire produtos ou serviços com fundamento na confiança depositada.

O pressuposto básico de toda relação de consumo é a existência de uma desigualdade jurídica e fática entre os sujeitos de direito que integram essa relação, haja vista que o fornecedor é o detentor dos meios de produção e, em razão disso, o consumidor é colocado em posição de absoluta subserviência e inferioridade, razão essa que justifica o tratamento jurídico especifico, de modo a assegurar a esse consumidor o direito de igualdade no âmbito da relação consumeirista.

Todas as vezes que essa desigualdade jurídica existente no plano contratual se reflete no contexto processual o consumidor passará a gozar casuisticamente do direito à inversão do ônus da prova. Se o autor da ação não tiver condições de provar os fatos por ele alegados torna-se indispensável a inversão do ônus da prova, para que seja assegurado ao consumidor a isonomia processual. Hoje é muito comum a aplicação da Teoria da Distribuição Dinâmica do Ônus da Prova, “cabendo ao magistrado atribuir o ônus da prova à parte que concretamente revele melhores condições de produzi-la” (OLIVEIRA, 2014, p. 88). Nessa seara pode-se afirmar que "ao juiz é facultado inverter o ônus da prova inclusive quando esta prova é difícil mesmo para o fornecedor, parte mais forte e expert na relação” (MANASSÉS, 2014) ${ }^{8}$.

Esse breve esclarecimento das questões e particularidades das relações consumeiristas, assim como das questões processuais inerentes ao debate de pretensões de natureza de consumo, é imprescindível para a compreensão da responsabilidade civil decorrente do descumprimento de obrigações estabelecidas no contrato de prestação de serviços na educação superior privada, debate esse que ocorrerá a seguir e que constitui objeto central da presente pesquisa científica.

fornecimento de produtos e serviços, nos termos do art. $4^{\circ}$, IV do mencionado diploma (OLIVEIRA, 2014, p. 86).

8 Disponível em http://www.conteudojuridico.com.br/artigo,vulnerabilidade-hipossuficiencia-conceito-deconsumidor-e-inversao-do-onus-da-prova-notas-para-uma-diferenciac,43983.html. Acesso em 25 jun. 2017. 


\section{Responsabilidade Civil Objetiva e as Perdas e Danos decorrentes do descumprimento} do Contrato de Prestação de Serviços Educacionais nas Instituições Privadas de Ensino Superior.

O pressuposto jurídico básico da teoria da responsabilidade civil no Brasil é a prática de uma conduta ilícita, que poderá advir da violação de uma obrigação contratual ou legal. O direito de perdas e danos decorre diretamente da comprovação do nexo de causalidade existente entre a ilicitude e o dano causado, ou seja, a simples prática de uma conduta ilícita não é suficiente para concluirmos pela presunção de um dano, haja vista que deverá ser comprovado em cada caso concreto.

No que tange especificamente ao tema-problema objeto da presente pesquisa cientifica, pode-se afirmar que o simples descumprimento de alguma obrigação contratual, seja pelo contratante ou contratado, não gera automaticamente direito a exigir perdas e danos. Tal esclarecimento torna-se relevante porque é comum escutar afirmações no sentido de que todo descumprimento de obrigação gera, por si só, uma pretensão de danos morais, o que nem sempre é verdade.

O contrato de prestação de serviços educacionais, em razão de suas peculiaridades, deve ser visto de forma particularizada quando se fala em responsabilidade civil em razão do seu descumprimento. Por ser regida pelo Código de Defesa do Consumidor, tal relação jurídica tem diretrizes legais que regulam a responsabilidade civil objetiva, cuja análise da conduta do agente torna-se dispensável quando se discute a possibilidade de perdas e danos. “A responsabilidade objetiva é aquela que independe da prova de culpa; ela se satisfaz apenas com a prova do dano e do nexo de causalidade” (OLIVEIRA, 2014, p. 142).

A ilicitude é o primeiro elemento jurídico-legal a ser comprovado, ressaltando-se que decorre da violação de uma obrigação contratualmente estabelecida entre as partes. Além da comprovação da conduta ilícita praticada pelo agente (seja o consumidor ou o fornecedor), é imprescindível demonstrar que tal conduta gerou um dano de natureza moral a parte lesada. A demonstração do nexo de causalidade entre a ilicitude e o dano é pressuposto básico para eventual discussão do tema proposto.

O simples descumprimento de obrigação prevista no contrato de prestação de serviços educacionais é insuficiente para presumirmos a configuração de danos morais. Por 
exemplo, o professor que não devolve a prova corrigida para o aluno descumpre o contrato de prestação de serviços e, por conseguinte, pratica uma ilicitude. A configuração do dano, nesse caso, deve ser comprovada, uma vez que o mesmo não é presumido.

O Dano Moral $^{9}$ vincula-se à violação de Direitos da Personalidade ou Direitos Fundamentais, elementos esses imprescindíveis para o reconhecimento da pretensão indenizatória. Caso a conduta ilícita não venha a lesar Direitos Fundamentais ou da Personalidade, não há que se falar em Danos Morais, mas, sim, em mero aborrecimento, não passível de indenização.

Uma situação que ilustra bem no âmbito educacional a pretensão de danos morais é aquela em que a Instituição de Ensino Superior se recusa a providenciar a expedição do diploma de conclusão de curso do aluno inadimplente. Trata-se de aluno que cumpriu todos os requisitos legais para a conclusão do curso e no momento em que a Instituição de Ensino se recusa a providenciar a expedição do diploma, justificando sua recusa no inadimplemento, viola o direito fundamental de exercício livre da profissão. Tal conduta ilícita, uma vez comprovada de forma idônea, legitima a pretensão de Danos Morais, uma vez que no presente caso temos a expressa ofensa de um direito fundamental.

Meros aborrecimentos são situações que geram desconforto, instabilidade mas são insuficientes para ocasionar a ofensa a um direito fundamental ou direito da personalidade; por esse motivo é insuficiente para assegurar a pretensão indenizatória. É muito comum no meio acadêmico condutas ilícitas ensejadoras do mero aborrecimento, como por exemplo, o professor que lança notas no sistema aula intempestivamente; o professor que deixa de entregar e devolver ao aluno as avaliações devidamente corrigidas; o aluno que conversa durante a aula e atrapalha o professor ministrar o conteúdo programático.

Em contrapartida, podemos destacar algumas situações que geram pretensão indenizatória de danos morais:

a) Professor que expõe a nota da avaliação de um aluno específico, publicizando a dificuldade em compreender o conteúdo programático e o expondo. Nesse caso torna-

\footnotetext{
${ }^{9} \mathrm{O}$ dano moral consiste na lesão de direitos cujo conteúdo não é pecuniário, nem comercialmente redutível a dinheiro. Em outras palavras, podemos afirmar que o dano moral é aquele que lesiona a esfera personalíssima da pessoa (seus direitos da personalidade), violando, por exemplo, sua intimidade, vida privada, honra e imagem, bens jurídicos tutelados constitucionalmente (GAGLIANO; PAMPLONA FILHO, 2006, p. 55).
} 
se viável e legitima a pretensão de indenização por danos morais em virtude da violação do direito fundamental à honra objetiva e subjetiva do discente.

b) Aluno que publica em redes sociais comentários infamantes dirigidos à pessoa de um determinado professor. A viabilidade da pretensão de danos morais no presente caso decorre da violação do direito fundamental à honra e ao nome do professor difamado, injuriado ou caluniado.

c) Recusa de expedição de diploma a aluno inadimplente que concluiu regularmente curso superior. Nesse caso é viável a pretensão de danos morais, decorrente da violação do direito dundamental ao exercício livre da profissão, além de eventual pretensão de Lucros Cessantes.

d) Instituição de Ensino Superior que insere indevidamente nome de aluno em cadastro de restrição de crédito. A pretensão de danos morais é juridicamente viável em virtude da violação do direito da personalidade ao nome.

e) Instituição de Ensino Superior que faz apologia ao racismo, discriminação de origem, raça, sexo, cor, idade, poderá ser condenada por danos morais em virtude da violação do direito fundamental à igualdade.

Esses são alguns exemplos para ilustrar os critérios jurídicos regentes ao reconhecimento da pretensão indenizatória de danos morais em caso de descumprimento de contrato de prestação de serviços educacionais.

A liberdade de cátedra não pode ser tolhida de modo a ensejar indevidamente a pretensão por danos morais. Um professor que ministra regularmente o conteúdo da disciplina e avalia coerentemente seus alunos não pode ser demandado em eventual ação de danos morais sob o argumento de excesso de rigorosidade metódica (o aluno não pode pretender processar o professor porque considera sua prova difícil).

Tais esclarecimentos jurídicos são relevantes em razão da necessidade de desmitificar a ideológica concepção da industrialização do dano moral. Ou seja, nem tudo é dano moral; mesmo diante de uma ilicitude decorrente do descumprimento de obrigação prevista no contrato de prestação de serviços educacionais sabe-se que o dano moral não é presumido, haja vista que precisa ser demonstrado e é consectário da violação de um direito da personalidade ou direito fundamental, conforme alhures mencionado. 


\subsection{Dano Moral decorrente do descumprimento do Contrato de Prestação de Serviços Educacionais por Instituições Privadas de Ensino Superior.}

O Dano Moral é considerado historicamente uma construção recente sob o ponto de vista jurídico-legal no Brasil. Previsto expressamente nos incisos V e X da Constituição brasileira de 1988, foi sistematizado na perspectiva de compensar a dor moral daquelas pessoas violadas em seus direitos fundamentais ou direitos da personalidade. Sua natureza jurídica é considerada o referencial teórico e balizador para nortear a quantificação. É sabido que no Brasil adotamos a natureza jurídica pedagógico-compensatória como meio de viabilizar sua reparação.

O Código Civil brasileiro de 1916 teve seu foco de análise e interpretação pautado no patrimônio, ou seja, protegia-se eminentemente a propriedade privada, uma vez que a pessoa humana era colocada para segundo plano. O Novo Código Civil brasileiro veio com a proposta de despatrimonializar o Direito Civil, de modo que a pessoa humana fosse o foco de preocupação e proteção jurídica. “Com a despatrimonialização do direito privado, alterou-se o foco do Direito Civil, do "ter" para a ideia do "ser", que se traduz no ideal de flexibilidade do sistema jurídico vigente, com fulcro na Constituição” (LACERDA, 2014) ${ }^{10}$.

A teoria da responsabilidade civil foi inicialmente delineada a partir da proposição de buscar a reparação pelos danos sofridos pela pessoa humana em razão de uma conduta ilícita praticada pelo agente, desde que a vítima do dano consiga comprovar o nexo de causalidade entre a conduta ilícita e o dano. Antunes Varela, citado por Sérgio Cavalieri Filho, afirma que “O elemento básico da responsabilidade é o fato do agente - um fato dominável ou controlável pela vontade, um comportamento ou uma forma de conduta humana - pois só quanto a fatos dessa índole tem cabimento a ideia da ilicitude, o requisito da culpa e a obrigação de reparar o dano nos termos em que a lei impõe” (2009, p. 8).

É sabido que a ilicitude supramencionada poderá decorrer de conduta dolosa ou culposa, omissiva ou comissiva do agente, uma vez que as excludentes de ilicitude afastam a responsabilidade civil justamente em virtude da ausência da prática da conduta ilícita reconhecida pelo direito pátrio, tal como ocorre, por exemplo, como o caso fortuito e a força

10 Disponível em http://ww3.lfg.com.br/public_html/article.php?story=20080306152644581\&mode=print. Acesso em 29 jun. 2017. 
maior. “Todo aquele que causar dano a outrem, seja pessoa física ou jurídica, fica obrigado a repará-lo, restabelecendo o equilíbrio rompido (CC, art. 186 c/c art. 927), cabendo ao lesado a prova, no caso concreto, do dolo ou culpa do agente” (DINIZ, 2008, p. 13).

No contexto do Direito Educacional, especificamente no que atine ao contrato de prestação de serviços educacionais por Instituições Privadas de Ensino Superior não é diferente. O direito à reparação por perdas e danos advém da comprovação do nexo de causalidade entre o ato ilícito e a concretude do dano de ordem moral. Não se pode presumir que a mera prática de conduta ilícita é suficiente a viabilizar o direito à reparação no âmbito do Direito Educacional.

A autonomia de cátedra e o exercício regular da atividade do professor não configura, por exemplo, a prática de dano moral, conforme preleciona decisão do Tribunal de Justiça de Rondônia:

Indenizatória. Dano moral. Sala de aula. Desvio de conduta. Adequação ao convívio coletivo. Ofensa de professor ao aluno. Não configuração. I O professor em sala de aula é detentor de prerrogativa de ascendência e autoridade necessárias ao exercício da elevação educacional e cultural do aluno e ajustamento desta conduta ao ambiente coletivo em que está inserido. II - A observação negativa sobre comportamento da aluna que desconsidera a convivência coletiva e adota conduta prejudicial ao ambiente necessário ao ensino na sala de aula insere-se no exercício regular da atividade do professor. III - Não configurando censura sobre vicio ou desvio de caráter, mas sobre o comportamento inadequado no ambiente coletivo de ensino, não fala em ofensa à honra ou danos morais, pois o exercício do magistério não é simplesmente repassar conteúdo programático formal, mas também o ajustamento e o valor à vida coletiva, ao modelo de boa convivência e inter-relacionamento social.200.007. Embragos Infringentes (TJRO, Embargos Infringentes EI 20000720050104442 RO 200.007.2005.010444-2, Data da Publicação 01/02/2008)

O caso acima mencionado ilustra a tentativa de industrializar o instituto do dano moral, de modo a buscar a judicialização do direito educacional como forma de intimidar e deslegitimar o exercício da atividade docente. Ofender a honra de aluno, com palavras de baixo calão, denegrindo publicamente a imagem e a honra do aluno perante outras pessoas acarreta condenação por danos morais ao agente. Nesse sentido temos recente jurisprudência do Tribunal de Justiça do Distrito Federal: 
CIVIL E PROCESSO CIVIL. AÇÃO DE REPARAÇÃO DE DANOS. PALAVRAS DE BAIXO CALÃO. OFENSAS DIRIGIDAS POR PROFESSOR A ALUNA NO AMBIENTE DE ENSINO. SALA DE AULA. DANO MORAL CONFIGURADO. DESNECESSIDADE DA PROVA DO PREJUÍZO. FIXAÇÃO DO QUANTUM. PROPORCIONALIDADE E RAZOABILIDADE. 1. CONFIGURA ATO ILÍCITO, APTO A JUSTIFICAR REPARAÇÃO POR DANOS MORAIS, A ATITUDE DO PROFESSOR QUE PROFERE DIVERSAS PALAVRAS DE BAIXO CALÃO CONTRA ALUNA, DE MODO OFENSIVO E EM TOM DE VOZ ALTERADO, REAGINDO À ATITUDE DA DISCENTE QUE, AGINDO DENTRO DE SEU DIREITO, SOLICITA REVISÃO DE MENÇÃO ATRIBUÍDA À SUA PROVA. 2. NA AÇÃO DE INDENIZAÇÃO POR DANOS MORAIS, EM SE TRATANDO DE OFENSAS PROFERIDAS CONTRA A AUTORA-ALUNA, DENTRO DA INSTITUIÇÃO DE ENSINO, NÃO SE FAZ NECESSÁRIA A PROVA DO PREJUÍZO, SENDO SUFICIENTE PARA A PROCEDÊNCIA A CONSTATAÇÃO DO NEXO DE CAUSALIDADE ENTRE O DANO E A CONDUTA DO OFENSOR. PRECEDENTE DO STJ. 3. NA FIXAÇÃO DA INDENIZAÇÃO POR DANOS MORAIS, DEVE CONSIDERAR O JUIZ A PROPORCIONALIDADE E RAZOABILIDADE DA CONDENAÇÃO EM FACE DO DANO SOFRIDO PELA PARTE OFENDIDA E O SEU CARÁTER COMPENSATÓRIO E INIBIDOR, MEDIANTE O EXAME DAS CIRCUNSTÂNCIAS DO CASO CONCRETO. 4. RECURSO NÃO PROVIDO.( TJ-DF - Apelação Cível APC 20130110794035 DF 0020423-55.2013.8.07.0001, Data da Publicação 01/04/2014)

Outro caso recente que ilustra claramente a problemática do dano moral no âmbito do Direito Educacional decorreu de uma pesquisa estatística no âmbito de uma escola municipal, momento em que houve uma avaliação subjetiva dos professores pelos alunos, que se utilizaram de expressões depreciativas e preconceituosas para questionar a orientação sexual do coordenador. Tais informações foram publicizadas e divulgadas abertamente no âmbito da escola, fato esse que acarretou o reconhecimento da pretensão de danos morais em virtude da ofensa à honra e a dignidade do coordenador. Esse caso não pode ser visto como mero dissabor, uma vez que o dano moral resta claramente comprovado no momento em que se verifica a violação do direito fundamental à honra e a dignidade humana, ressaltando-se que tal condenação decorreu do nexo de causalidade existente entre o dano sofrido pelo coordenador e a conduta ilícita omissiva da escola, na pessoa de seu gestor, em evitar a divulgação aberta dos resultados da pesquisa com o animus de ofender e atentar contra a honra da vítima em razão de sua orientação sexual. Nesse sentido temos o entendimento do Tribunal de Justiça de Minas Gerais: 
AÇÃO DE INDENIZAÇÃO - REALIZAÇÃO DE "PESQUISA ESTATÍSTICA" NO ÂMBITO DE ESCOLA MUNICIPAL AVALIAÇÃO SUBJETIVA DOS PROFESSORES PELOS ALUNOS UTILIZAÇÃO DE EXPRESSÕES DEPRECIATIVAS E PRECONCEITUOSAS PARA QUESTIONAR A ORIENTAÇÃO SEXUAL DE COORDENADOR NOMEADO ABERTAMENTE - DIVULGAÇÃO DO CONTEÚDO DA PESQUISA NO ÂMBITO DA ESCOLA - DANOS MORAIS - OFENSAÀ HONRA E DIGNIDADE - CONSTRANGIMENTO NO ÂMBIENTE DE TRABALHO - RESPONSABILIDADE OBJETIVA DO ENTE PÚBLICO POR ATO PRATICADO POR AGENTE SEU - ART. 37 , § $6^{\circ}$, DA CF/88 . DENUNCIAÇÃO DA LIDE - AUSÊNCIA DE OBRIGATÓRIEDADE - PRECEDENTES DO STJ. (TJ-MG - Apelação Cível AC 10083120014838001 MG (TJ-MG) - Data de publicação: 10/07/2013)

Outro caso bastante ilustrativo para a discussão e análise do tema dano moral no âmbito do Direito Educacional diz respeito a professor que em sala de aula, em estado comprovadamente etílico, ofende verbalmente aluna, constrangendo-a e humilhando-a na presença dos demais alunos. Nesse caso, o Tribunal de Justiça do Distrito Federal responsabilizou objetivamente a Instituição de Ensino por entender que a ofensa ao direito fundamental à honra da aluna ocorreu em razão da conduta ilícita omissiva da instituição que autorizou que professor adentrasse à sala de aula em estado etílico. Quanto à quantificação do valor dos danos morais adotou-se a natureza pedagógica, compensatória e punitiva, com a finalidade de desestimular novamente a prática dessa conduta e, também, exigir da Instituição de Ensino maior zelo e cuidado com relação aos docentes contratados para ministrarem aulas. Nesse sentido temos o entendimento do Tribunal de Justiça do Distrito Federal

CIVIL. PROCESSUAL CIVIL. CDC . ESTABELECIMENTO DE ENSINO. INDEFERIMENTO DE OITIVA DE TESTEMUNHAS. CERCEAMENTO DE DEFESA. INEXISTÊNCIA. PROFESSOR EM SALA DE AULA EM ESTADO ETÍLICO. OFENSA VERBAL A ALUNA. DANO MORAL CARACTERIZADO. REPARAÇÃO DEVIDA. JUSTO VALOR ( TJ-DF - APELAÇÃO CÍVEL NO JUIZADO ESPECIAL ACJ 20060810002473 DF (TJ-DF) Data de publicação: 07/12/2006)

Outra questão relevante diz respeito aos casos de ofensa à honra e à liberdade de expressão do aluno pelo professor. Infelizmente tal situação tem sido muito comum no meio acadêmico na atualidade, certamente em razão da clássica concepção de que o professor é a 
autoridade em sala de aula, detentora de uma sapiência inata, concepção essa que acaba o levando a tratar seus alunos muito mais como coisa do que propriamente como sujeitos diretamente legitimados à construção do conhecimento científico.

A pretensão de danos morais torna-se viável quando esses abusos praticados por docentes deflagram a violação da dignidade humana e ofensa à honra do aluno, muitas vezes perseguido, humilhado publicamente, exposto indevidamente perante os demais colegas e reprovado pela utilização de critérios subjetivos de avaliação. Se ainda discutimos danos morais decorrente da ofensa à honra e a liberdade de expressão cientifica em sala de aula é porque continuamos a conviver com um modelo de ensino autocrático, em que muitos docentes se consideram dotados de conhecimento supremo que os legitimariam de forma indevida a tratar seus alunos não como sujeitos, mas sim, como objetos do processo ensinoaprendizagem. A problemática do dano moral no âmbito das instituições de ensino superior privadas decorre de abusos praticados por discentes, docentes ou corpo administrativo. Sempre que tais condutas ensejarem ofensa a direitos fundamentais ou da personalidade a pretensão indenizatória torna-se juridicamente viável.

\section{Caso Geisy Arruda e Uniban: uma análise jurídica da pretensão de Danos Morais}

No dia 22 de outubro de 2009 a acadêmica Geizy Arruda foi xingada e humilhada nos corredores da universidade pelo fato de usar um microvestido rosa. Logo após o incidente, a Uniban resolveu expulsar a respectiva aluna, mas recuou em sua decisão, no momento em que percebeu a repercussão de tal episódio nas redes sociais e na imprensa.

Em razão de tais fatos, o Tribunal de Justiça de São Paulo condenou a Uniban a indenizar a então estudante universitária por danos morais no valor de R \$ 40.000,00 (quarenta mil reais), ressaltando-se que tal valor foi fixado pela primeira instância e confirmado pela segunda instância. À época a autora da ação pleiteou uma indenização no valor de um milhão de reais, pedido esse julgado parcialmente procedente, haja vista que na quantificação do dano moral o Judiciário paulista levou em consideração as peculiaridades do caso concreto, as provas produzidas nos autos e a extensão dos efeitos da conduta ilícita praticada pela Uniban.

Inicialmente é importante identificar no presente caso a conduta ilícita ora praticada pelo agente. É sabido que constitui obrigação assumida contratualmente pela Uniban garantir 
a segurança, a integridade física, moral e psicológica de todos os seus acadêmicos. Trata-se de cláusula implícita ou explicitamente prevista no contrato de prestação de serviços educacionais.

Constitui obrigação da Instituição de Ensino disponibilizar seguranças e serviços de vigilância com a finalidade de prevenir ou evitar a prática de condutas ou a ocorrência de fatos que venham a culminar com a violação de direitos fundamentais ou direitos da personalidade de seus alunos. A ausência ou a ineficiência na prestação do serviço de segurança ou vigilância caracteriza, por si só, a omissão da Instituição de Ensino Superior, que, em razão do ocorrido submeteu sua acadêmica a uma comprovada situação de absoluta ofensa ao direito fundamental à honra objetiva e subjetiva.

No caso em tela, afirma-se que a Uniban praticou conduta ilícita omissiva, ou seja, deixou de prestar de forma efetiva ou prestou de forma ineficiente o serviço de segurança e vigilância, de modo a evitar que o tumulto que ensejou a humilhação e os xingamentos ao qual foi submetida a aluna Geisy Arruda fosse evitado. No momento em que a Instituição de Ensino Superior autorizou (expressa ou tacitamente) ou permitiu a entrada da aluna em suas dependências com “o tal microvestido rosa”, assumiu a obrigação contratual e o dever legal de garantir sua integridade física, moral e psicológica. Ou seja, a instituição em tela deveria ter evitado ou reprimido qualquer tumulto, humilhação ou xingamento à aluna, algo que não ocorreu, uma vez que a acadêmica, à época, foi exposta e julgada moralmente de forma sumária pelos demais estudantes em virtude da comprovada omissão da Instituição de Ensino Superior.

Importante destacar, no presente caso, que existe uma relação de consumo entre a discente e a Instituição de Ensino Superior. Geisy Arruda encontrava-se na condição de consumidora, uma vez que contratou a prestação de serviços educacionais como destinatária final. A Uniban assumiu juridicamente a condição de fornecedora, tendo em vista que se trata de pessoa jurídica que exerce a atividade fim de prestação de serviços educacionais.

O caso em tela ilustra bem a problemática tratada na presente pesquisa, qual seja, uma situação específica ocorrida no âmbito acadêmico que acarretou a responsabilidade civil objetiva e a condenação da Instituição de Ensino Superior (Uniban) a pagar a acadêmica Geisy Arruda indenização por danos morais decorrente de conduta ilícita omissiva, que 
acarretou a violação do seu direito fundamental à honra, dignidade humana, integridade moral, psicológica e iminente violação a sua integridade física. Trata-se de exemplo utilizado como parâmetro à reflexão cientifica das obrigações assumidas contratualmente pelas Instituições de Ensino Superior Privado, demonstrando-se que o descumprimento de algumas obrigações previstas no contrato de prestação de serviços educacionais são suficientes a ensejar o reconhecimento da pretensão de reparação por perdas e danos.

\section{Conclusão}

O contrato de prestação de serviços educacionais firmado entre discente e instituição privada de ensino superior é regido pelo Código de Defesa do Consumidor. O consumidor (discente) é considerado juridicamente vulnerável e a parte mais fraca da relação contratual, facultando-se a inversão do ônus da prova quando comprovado no caso concreto sua hipossuficiência em processo judicial. A responsabilidade civil objetiva dispensa a comprovação de conduta dolosa ou culposa do agente, bastando a demonstração do nexo de causalidade entre o dano e a conduta ilícita do agente.

O descumprimento do contrato de prestação de serviços educacionais caracteriza-se por ser conduta ilícita, embora não enseje automaticamente o dever de indenizar. A pretensão de danos morais somente se torna juridicamente viável quando um direito fundamental ou direito da personalidade comprovadamente for violado em razão da ilicitude contratual.

Meros aborrecimentos não são passíveis de reparação por inexistir a comprovação do nexo de causalidade entre o dano e a ilicitude do agente. A negativa de expedição de diploma de ensino superior em razão da inadimplência do discente; agressão física ou violência à integridade moral ou psicológica no âmbito institucional; condutas comissivas praticadas pelo docente contrariamente à honra objetiva ou subjetiva do discente; condutas comissivas praticadas pelo discente contrariamente à integridade física, moral ou psicológica do docente no âmbito institucional são algumas situações fáticas que ilustram a viabilidade de pretensão de danos morais pela vítima.

A comprovação do nexo de causalidade entre a ilicitude do agente e o dano sofrido pela vítima gera o dever de indenização. A responsabilidade civil da instituição privada de ensino superior decorre de condutas ilícitas comissivas ou omissivas contrariamente aos direitos fundamentais ou direitos da personalidade do discente. 
A quantificação do dano moral decorre da comprovação de sua extensão e de seus efeitos na vida da vítima, devendo ser razoável e proporcional para não gerar enriquecimento sem causa. A desproporcionalidade na quantificação do valor do dano moral ocasiona o enriquecimento indevido da vítima, contrariando a natureza pedagógico-compensatória da reparação.

Não reconhecer a possibilidade de reparação por danos morais é reconhecer as instituições privadas de ensino superior como um espaço que legitima a prática de ilicitudes. Nesse sentido, o processo judicial deve ser visto como o locus de alegação e comprovação dos fatos controversos que integram a demanda, além de legitimar a construção participada do provimento jurisdicional por todos aqueles sujeitos juridicamente interessados. Trata-se de um meio legítimo de compensar monetariamente prejuízos de ordem moral sofridos pelas vítimas no âmbito institucional.

\section{Referências}

BOU-KARIM, Márcia Fabiana Lemes Póvoa; CORDEIRO, Uberth Domingos. Mero Aborrecimento X Dano Moral. Disponível em https://juridicocorrespondentes.com.br/artigos/marciapovoa/mero-aborrecimento-X-danomoral-208?gclid=CLP-79PZ7MICFWsF7Aod9RMAug. Acesso em 29 jun. 2017. BRASIL. Conceito, Requisitos e Princípios dos Contratos. Disponível em http://www.centraljuridica.com/doutrina/78/direito_civil/conceito_requisitos_principios_dos_ contratos.html. Acesso em 20 jun. 2017.

CANUTO, Vera Regina Albuquerque. Politicos e Educadores: a organização do ensino superior no Brasil. Petrópolis: Editora Vozes, 1987.

CAVALIERI FILHO, Sérgio. Programa de Responsabilidade Civil. 8. ed. São Paulo: Atlas, 2009.

DINIZ, Maria Helena. CURSO DE DIREITO CIVIL BRASILEIRO. Responsabilidade Civil. 22. ed. São Paulo: Saraiva, 2008.

DINIZ, Maria Helena. CURSO DE DIREITO CIVIL BRASILEIRO. Teoria das Obrigações Contratuais e Extracontratuais. 24. ed. São Paulo: Saraiva, 2008. 
FREIRE, Paulo. PEDAGOGIA DA AUTONOMIA - Saberes necessários à prática educativa. São Paulo: Paz e Terra, 2011.

GAGLIANO, Pablo Stolze; PAMPLONA FILHO, Rodolfo. Novo Curso de Direito Civil Contratos. Tomo 1, v. IV, 2. ed. São Paulo: Saraiva, 2006.

GAGLIANO, Pablo Stolze; PAMPLONA FILHO, Rodolfo. Novo Curso de Direito Civil Responsabilidade Civil. v. III, 4. ed. São Paulo: Saraiva, 2006.

GOMES, Magno Federici. DIREITO EDUCACIONAL SUPERIOR -Evolução histórica, legislação, procedimentos administrativos e função normativa. Curitiba: Juruá, 2012. GONÇALVES, Carlos Roberto. Direito Civil Brasileiro. 3. ed. São Paulo: Saraiva, 2007. LACERDA, Leydslaine Israel. A desparimonialização do Direito Civil. Disponível em http://ww3.lfg.com.br/public_html/article.php?story=20080306152644581\&mode=print. Acesso em 29 jun. 2017.

MANASSÉS, Diogo Rodrigues. Vulnerabilidade, hipossuficiência, conceito de consumidor e inversão do ônus da prova: notas para uma diferenciação. Disponível em http://www.conteudojuridico.com.br/artigo,vulnerabilidade-hipossuficiencia-conceito-deconsumidor-e-inversao-do-onus-da-prova-notas-para-uma-diferenciac,43983.html. Acesso em 25 jun. 2017.

NICOLAU JUNIOR, Mauro; NICOLAU, Célia Cristina Munhoz Benedetti.

Responsabilidade Civil dos Estabelecimentos de Ensino - A eticidade constitucional.

Disponível em: http://portaltj.tjrj.jus.br/c/document_library/get_file?uuid=e872eef2-16294321-85da-d52571b206e7\&groupId=10136. Acesso em 08 jun. 2017.

OLIVEIRA, Julio Moraes. Curso Direito do Consumidor Completo. Belo Horizonte: D’Plácido, 2014.

PRETTI, Gleibe. O Contrato de Adesão no Código de Defesa do Consumidor. Disponível em http://www.direitonet.com.br/artigos/exibir/725/O-contrato-de-adesao-no-Codigo-Brasileirode-Defesa-do-Consumidor. Acesso em 17 jun. 2017.

VENOSA, Silvio de Salvo. DIREITO CIVIL Teoria Geral das Obrigações e Teoria Geral dos Contratos. v. 2. São Paulo: Saraiva, 2011. 